\title{
The Effectiveness of Using the Blended Learning at the University of Jordan from the Students' Viewpoint in Teaching Learning Skills and Scientific Research Course
}

\author{
Nida'a Maen Salah \\ Deanship of Scientific Research \University of Jordan
}

\begin{abstract}
The study aims to measure the effectiveness of using blended learning at the University of Jordan from the students' viewpoint in teaching the learning skills and scientific research course. To achieve the objectives of the study, the descriptive survey method is used as a method to collect data as it is one of the appropriate approaches for such studies constructed on a questionnaire. The study population consists of 3500 male and female students of the blended learning courses (learning skills and scientific research course) from various levels and academic years according to the list of all candidates for the system of the blended learning courses for (2019-2020) at the University of Jordan. The study sample consists of 750 students based on the distribution of the study sample according to the study variables. The study shows that there are no statistically significant differences at the level of $(\alpha=0.05)$ due to the effect of gender, as the value of $F$ is 0.003 and with a statistical significance of 0.855 . It also shows that there are no statistically significant differences at the level of $(\alpha=0.05)$ due to the effect of the type of faculty, as the value of $\mathrm{F}$ is 1.004 and with a statistical significance of 0.422 . The study recommends introducing students to the theatrical and practical importance of blended learning and conducting other studies looking at the effectiveness of blended learning from the viewpoint of faculty members.
\end{abstract}

DOI: $10.7176 / \mathrm{JEP} / 11-20-06$

Publication date:July $31^{\text {st }} 2020$

\subsection{Introduction}

The present-day era observes many modern technological developments in the whole scientific and practical areas of life. These developments tremendously expand to include the field of education to bring about numerous changes in education systems that represent the mainstay in the progress of peoples and nations. Examining education in general, it is found that it depends in many of its stages on the traditional education in which the greatest burden falls on the teacher, and the role of the learner is largely negative. Therefore, many educational institutions seek to improve education by finding new ways aimed at the learner being active and positive, and the teacher is a mentor and a guide to improve and develop education and achieves the best educational results with high quality.

Ashhab (2015) maintains that traditional education alone is no longer sufficient to keep pace with modern thought and intellectual development. Consequently, the tendency to apply supportive educational mechanisms such as e-learning has the potential to improve, support, and build a distinct generation to develop the educational level and raise it to the highest levels to be on a par with technological development. Salama (2005) and Abdelatti (2016) indicate that technological development, no matter how it has grown and developed, will not replace the traditional methods of teaching and learning. On contrary, the e-learning cannot replace the existing traditional learning to the point that we disregard and ignore it, as it is impossible in our time to ignore modern electronic technology such as the Blended Learning.

The blended learning has emerged as a new method in education that combines the traditional method of face-to-face education with its characteristics and advantages, and e-learning with its virtual learning environment. With that, blended learning combines the optimal features between the traditional and electronic learning to suit the characteristics of learners and the goal to be achieved at the end of the educational semester. The advantages in traditional teaching methods and e-learning complete each other; hence the word "Blended" is coined by blending and mixing the two methods of education, and what they carry from tools and tasks. So, blended learning is considered a method in learning that contributes to facilitating education, communicating knowledge, and managing educational classes in a manner that takes into account the cognitive and technical aspects of learners. The American Society for Training and Development defines blended learning as one of the best trends emerging in the knowledge industry (Kiviniemi, 2014).

With the mutual use of modern technologies and study materials in the classroom, a process of designing an integrated instruction based on the use and employment of these technologies begins and is termed as e-learning by including e-learning systems in its instructional programs (Amer, 2015.(

One of these prominent systems is the e-learning system "Moodle" that has appeared in many countries of the world including the Hashemite Kingdom of Jordan, where it appeared in Jordan at the level of universities, institutes, and schools levels. The Moodle system is one of the technological education systems featured with a 
large number of educational advantages. It is based on simple and easy commands that do not require the teacher to be skilled in using technology and allows downloading various types of written, visual, and audio educational materials. Moreover, this system is intended to create learning and discussion forums, send short emails, and most importantly, develop the learning capabilities of its users like learners. The Moodle system also provides communication between all parties to the educational process as it aims to raise the efficiency of e-learning by creating interconnected infrastructure, distributed electronic content, and various interrelationships between the learner and teacher. The Moodle system has achieved the best results concerning its many functions, which have greatly assisted in managing the educational process, bringing an effective impact on the accreditation of educational institutions on it (Zboun and Hamdi) 2017).

Among the benefits of the e-course system for both the teacher and the learner and the educational institution as indicated by Talaba (2010) and Zamil (2017) are seen on the ability of the learner to select the information and experience he needs at the appropriate time and at the speed that suits him, so he is not related to the dates of classes or study schedules. Also, he can learn in an environment of privacy in isolation from others to repeat the learning process as much as he needs without feeling fear and embarrassment. The system also provides a tremendous amount of information without the need to search in the libraries. Moreover, it develops the skills of using the computer and the Internet through dealing with the contents of the electronic course, provides the teacher with time and effort to mentor, guide, and prepare student activities and focus on the skills that learners need, offers various forms of interaction between the teacher and the learner, and focuses on the feedback of the learner to guide him for the right path of learning. Furthermore, it saves the costs of printing, binding, storage, etc., reduces the costs of publishing compared to traditional publishing and delivers it to learners anywhere, and quickly updates the educational material and provides learners with it, along with easiness of correcting mistakes the moment they are discovered.

\subsection{Problem of the Study}

The interest in education technology has increased due to its multiple roles and contribution to developing the blended learning process and the learner's mastery of information. Achieving these roles requires an integrated system of the most important factors such as the availability of educational technology, the recruitment of qualified faculty members to communicate information to the student and motivate him to use it, and benefit from it in education and self-learning.

Bearing in mind the rapid advancement of educational technology and its impact on the teaching process, the use of technology in education has become an effective means of developing these methods, techniques, and strategies. Thus, it is necessary to prepare learners who possess skills and experiences that enable them to deal with the data of the current time and its challenges, along with the need for awareness of technological developments and investing their potential in the field of education (Zboun, 2015). Despite the importance of employing the E-Learning Management System in education as confirmed by the results of Faraj's study (2012), Assaf's study (2014) and Barakat's study (2014) and the Zboun's study (2015), the current reality of employing the E-Learning Management System for blended learning method and its related courses have not been studied from the viewpoint of faculty and students at the University of Jordan.

Coinciding with the urgent need to deal with modern technologies and theories in the world of teaching and learning and employing technology to serve the education process, the trend has increased at the University of Jordan to integrate electronic academic courses within the e-learning environment through the E-Learning Management System as this is the first experience in education at the University of Jordan. Thus, it is essential to know the reality of use, the pros and cons, and the nature of the changes caused by the E-Learning Management System in blended learning. Also, several studies point to the importance of using blended learning in learning and its positive effects and advantages on academic achievement, which increases students 'motivation towards learning such as the study of Anzi (2109), Hayari (2019), Dershwi (2019), and (Shihab, 2008, Munoz \& Towner, 2009) through the ability to employ modern learning and teaching methods instead of the traditional methods and the creation of e-learning societies and platforms. However, reliance on the blended learning and its applications in the teaching process in universities, their actual use, and benefiting from its advantages in raising the level of the educational learning process is still limited in Jordanian universities. Against this, the problem of the study lies in exploring the effectiveness of the use of blended learning at the University of Jordan from the students' viewpoint in teaching Learning Skills and Scientific Research Course.

\subsection{Questions of the Study}

In light of the problem of the study, the following questions are articulated.

1. How effective is the use of the blended learning at the University of Jordan from the students' viewpoint in teaching learning skills and scientific research course?

2. Are there statistically significant differences at the level of significance $(a=0.05)$ in the extent of the effectiveness of using blended learning at the University of Jordan from the students' viewpoint in teaching 
learning skills and scientific research course due to the variables of type of faculty and gender?

\subsection{Objectives of the Study}

The following objectives are formatted to answer the questions of the study.

Measure the effectiveness of using the blended learning at the University of Jordan from the students' viewpoint in teaching the learning skills and scientific research course.

Compare the effectiveness of using blended learning at the University of Jordan from the students' viewpoint in teaching learning skills and scientific research course due to the variables of type of faculty and gender.

\subsection{Significance of the Study}

This current study's contribution lies in several aspects such as providing those concerned with university administration, faculty members in universities and others with recommendations related to the importance of using electronic courses in university education, providing an experimental basis for using learning incorporated into the educational process as an alternative to reduce the burden on students, providing an information base that contributes to planning curricula in all Jordanian universities in the light of using blended learning and its effects, planning programs or training and educational workshops for teachers on how to use this technology in education, and helping decision-makers in the educational field and the makers of plans by highlighting the degree of possessing the necessary skills to use the blended learning in the educational-learning process. The importance is also seen in addressing the latest trends in the educational process, which is the blended learning, assisting officials and educators at the University of Jordan in planning and developing educational plans in a manner that is compatible with the E-Learning Management System and blended learning strategies and contributing to the transition to a knowledge society that focuses on the introduction of communication and information technology. Researchers in the field of educational technology can benefit from the recommendations and results of the study and considering them to develop teaching methods, and conducting similar field studies to develop a vision to improve performance in the era of information explosion.

\subsection{Previous studies}

Several studies have been written on the use of blended learning in the educational process and its effects on the academic achievement of students. In this regard, Abdeljawad (2011) conducts a study entitled Achieving ELearning Effectiveness in the Context of Egyptian Higher Education in Egypt. The importance of this study stems from the importance of applying and assessing the quality of the educational process, whether directly or through e-learning, as it is important to ensure the process of developing knowledge and understanding of learners. The researcher uses a case study as an instrument to examine the effectiveness of e-learning in the context of Egyptian higher education. To create a model for applying and assessing the efficiency of the elearning system, several methods are adopted to collect data, including interviews, questionnaires, feedback, and pre-publication test. The study describes the attitudes of participants towards e-learning as high-quality elearning systems and critical success factors for the development of Egyptian higher education systems, and how they view the effectiveness and quality of e-learning systems. The study indicates that the majority of participants are satisfied with the use of e-learning systems in their learning, as long as critical success factors are applied. Also, the study indicates that e-learning has a positive impact on learners' achievement levels.

In a study conducted by (2014, Gomes) entitled Blended Learning and Self-efficacy of the Student: An explanatory analysis of the phenomenon, he explores if there is a relationship between blended learning and the self-efficacy of students of community colleges, as noted by the teachers of the blended learning courses in these colleges. The current study examines Pandora's theory of self-efficacy using the structural structure of Vygotsky and Dede online theory which includes blended learning, and other theories that support the theoretical basis for Pandora. To determine whether blended learning increases the student's self-efficacy, teaching staff analysis has been explored through explanatory analysis as a qualitative view of the opinion of faculty members. The study shows that faculty members believe that students are not appropriately prepared for blended learning and that participation and interaction between students and the faculty and topics taught are critical factors in a student's self-efficacy and success in the teaching process. Also, the study shows that blended learning requires a greater effort from students and faculty in the mechanism of providing educational material and the increasing use of blended learning in university education. The study recommends paying more attention to the participation of students and faculty when preparing teaching courses and courses to guide student participation for blended learning.

In another study conducted by (2016, Maestas) entitled The Impact of Enhanced Teacher Feedback on Academic Outcomes of Students at Risk of Failure in Blended Learning Environments, the purpose of this quantitative pilot study is to use a different design to examine the impact of enhanced teacher feedback on academic outcomes of students at risk of failure in blended learning environments in Arizona, USA. The study 
sample includes (158) students from the ninth grade to the twelfth grade. The data is collected through academic capabilities, student participation, and performance in a blended learning course entitled "Accessing Your Account". Multivariate analysis of covariance (MANCOVA) is used to analyze the data. The results indicate that the enhanced feedback for teachers has no significant effect on course completion rates or course grades gained. However, educators must continue to explore and identify other factors that positively impact learners' academic outcomes in blended learning environments. The study recommends redoing this study within a different time frame, use a qualitative design, or use a basic academic course.

In consideration of the significance of this system, the University of Jordan, as the largest university education institution in Jordan, has included the electronic academic courses within its educational system of the E-Learning Management System to work alongside traditional education and achieve the desired learning outcomes. Importantly, the University adopts this new system and encourages its faculty members to use it to support various academic courses.

Of note, the forgoing studies are used to design the theoretical framework and develop the instrument. Also, the current study differs from previous studies as it addresses the reality of employing the e-learning management system from the viewpoint of teachers of the blended learning courses and their students at the University of Jordan. Moreover, this study is considered one of the first studies to address this topic in Jordan.

\subsection{Terms of the Study}

Due to the nature of the study, the following terms are adopted:

1. Blended learning: It is a mixture of face-to-face learning and e-learning through the use of assistive educational media (Abdelatti, 2016). It is procedurally defined as a method based on employing e-learning with the traditional education system and the direct interactions it provides and training in performing skills to achieve the greatest benefit in the educational process in the classrooms at the University of Jordan.

2. Blended learning courses: It is educational content used in its design for computer-based and interactive multimedia educational activities and materials in the form of software based on a local network or the Internet and displayed inside the classroom (Abdelatti, 2016). It is procedurally defined as the information, situations, and educational and electronic meetings provided to the learner through multimedia, which take place in real classrooms equipped with the ability to connect to networks.

3. The reality of employment: It is the use of improvement and development (Ashhab, 2015). It is procedurally defined as the expected and effective use of the teacher and learner for teaching techniques to employ them on time to enrich and improve the blended learning and teaching situations through the E-Learning Management System at the University of Jordan.

4. Students of the blended learning courses: They are the learners who receive computer-based educational content displayed inside the classroom (Abdelatti, 2016). They are procedurally defined as the students registered in the blended courses within the E-Learning Management System at the University of Jordan.

\subsection{Limitations of the Study}

This study is limited to study the reality of employing the e-learning management system from the viewpoint of teachers of the blended learning courses and their students at the University of Jordan. It is also limited to the students of learning and scientific research skills at the University of Jordan. Moreover, it is applied in the $2^{\text {nd }}$ semester of the academic year 2019/2020. The results of this study are limited by its population study, the degree of responses of sample study's members, and the nature of its instruments and variables.

\subsection{Methodology of the Study}

In this study, the descriptive survey method is used as a method to collect data as it is one of the appropriate approaches for such studies constructed on a questionnaire.

\section{Study Population}

The study population consists of 3500 male and female students of the blended learning courses (learning skills and scientific research course) from various levels and academic years according to the list of all candidates for the system of the blended learning courses for (2019-2020) at the University of Jordan.

\section{Study Sample}

The study sample consists of 750 students based on the distribution of the study sample according to the study variables. 
Table 1

Frequencies and Percentages According to the Study Variables

\begin{tabular}{|l|l|l|}
\hline \multirow{2}{*}{ Gender } & Categories & Frequencies \\
\cline { 2 - 3 } & Male & 300 \\
\cline { 2 - 3 } & Female & 450 \\
\hline & Humanities & 377 \\
\cline { 2 - 3 } & Scientific & 373 \\
\hline & Total & 750 \\
\hline
\end{tabular}

Study Insturments

This study aims to identify the effectiveness of using blended learning at the University of Jordan from the students' viewpoint in teaching learning skills and scientific research. To achieve these objectives, a questionnaire is developed to measure the effectiveness of using the blended learning at the University of Jordan from the students' viewpoint in teaching learning skills and scientific research course, as the special study instrument consists of two parts:

First: It includes general information about the study sample's members in light of the following variables (gender, type of faculty).

Second: It included the main areas of the subject of the effectiveness of using blended learning at the University of Jordan from the students' viewpoint in teaching the learning skills and scientific research course. The researcher uses a five-level measure (Strongly disagree, Disagree, Neither agree nor disagree, Agree, Strongly Agree.

The scale of the effectiveness of using the blended learning at the University of Jordan is corrected from the students' viewpoint in teaching learning skills and scientific research course as follows: Strongly agree (5 grades), agree (4 grades), neither agree nor disagree (3 grades), strongly disagree (2 grades), disagree (1 degree). The following measure is adopted to analyze the results:

From 1.00 to 2.33 low

From 2.34 to 3.67 medium

From 3.68 to 5.00 is high

Instrument Validity and Reliability

To verify the validity of the content of the study instrument of the measures of the effectiveness of using the blended learning at the University of Jordan from the students' viewpoint in teaching learning skills and scientific research course, the content is presented to 10 experts and specialists in the fields of education technology, curricula, teaching, measurement, and evaluation to express their opinions on it in terms of the linguistic formulation of the items, their clarity, and relevance to the areas of the effectiveness of using the blended learning at the University of Jordan from the students' viewpoint in teaching the learning skills and scientific research course that fall within it, where the measure is modified according to the consensus of the majority of the validators. To verify the reliability of the instrument, the internal consistency of an exploratory sample from outside the study sample of (100) male and female students is calculated according to the Alpha Cronbach equation. Table (2) shows these coefficients and percentages considered appropriate for this study.

Table 2

The Internal Consistency Coefficient of the Cronbach Alpha

\begin{tabular}{|l|l|}
\hline Fields & $\begin{array}{l}\text { Internal } \\
\text { Consistency }\end{array}$ \\
\hline The reality of blended learning at the University of Jordan & $\mathbf{0 . 8 9}$ \\
\hline $\begin{array}{l}\text { The reality of employing an E-Learning Management System for blended learning } \\
\text { courses }\end{array}$ & $\mathbf{0 . 9 0}$ \\
\hline Students' viewpoint towards blended learning and its courses & $\mathbf{0 . 9 0}$ \\
\hline Total degrees & $\mathbf{0 . 9 0}$ \\
\hline
\end{tabular}

\section{Construct Validity (Students)}

To evaluate the significance of construct validity for the measure, the correlation coefficients of the measure's items with the total degree in an exploratory sample from outside the 100-student study sample are calculated. The measure's items are analyzed and the correlation coefficient is calculated for each of the items, where the correlation coefficient represents a sign of validity for each item in the form of a correlation coefficient between each item and the total degree on the one hand, and between each item and its correlation with the field to which it belongs, and between each field and the total degree on one hand, and the coefficients of item correlation with the instrument as a whole has ranged between $(0.50-0.87)$ and with the field (0.47-0.90)

\section{Study Variables}

Taxonomic independent variables including:

Type of faculty: It has two levels (humanitarian and scientific). 
Gender: It has two levels (male, female).

Results Discussion:

Q1. How effective is the use of blended learning at the University of Jordan from the students' viewpoint in teaching learning skills and scientific research course?

To answer this question, arithmetic means and standard deviations are calculated from the estimates of students of the blended learning courses at the University of Jordan on the reality of employing the e-learning management system as shown in Table (3).

Table 3

Arithmetic Means and Standard Deviations for Students' Blended Learning Courses' Estimates at the University of Jordan on the Effective Use of Blended Learning in Teaching Learning Skills and Scientific Research Course in Descending Order by Arithmetic Means

\begin{tabular}{|l|l|l|l|l|}
\hline Rank & Field & AM & SD & $\begin{array}{l}\text { Degree } \\
\text { Estimate }\end{array}$ \\
\hline 1 & Students' viewpoint towards blended learning and its courses & 3.45 & .808 & Medium \\
\hline 2 & $\begin{array}{l}\text { The reality of employing an E-Learning Management System for } \\
\text { blended learning courses }\end{array}$ & 3.39 & .785 & Medium \\
\hline 3 & The reality of blended learning at the University of Jordan & 2.98 & .817 & Medium \\
\hline & \multicolumn{2}{|l}{3.30} & .689 & Medium \\
\hline
\end{tabular}

Table (2) shows that the arithmetic means have ranged between (2.98-3.45), where the item (1) which states " Students' viewpoint towards blended learning and its courses " is ranked first with the highest arithmetic mean of (3.45), while item (2) which states "the reality of blended learning at the University of Jordan" is ranked last with an arithmetic mean of (3.30), and the arithmetic mean for the instrument as a whole is (3.30). The arithmetic means and standard deviations for the estimates of the study sample members on the items of each field are separately calculated as follows:

The first field: The reality of blended learning at the University of Jordan in terms of:

a. Infrastructure and basic equipment

Table 4

The Arithmetic Means and the Standard Deviations for the Items Related to Infrastructure and Basic Equipment in Descending Order According to the Arithmetic Means

\begin{tabular}{|l|l|l|l|l|}
\hline Rank & Items & AM & SD & Degree \\
\hline $\mathbf{1}$ & $\begin{array}{l}\text { The university provides students with access to electronic libraries to } \\
\text { access scientific references. }\end{array}$ & 3.40 & 1.155 & Medium \\
\hline $\mathbf{2}$ & The university provides students with internet service. & 3.22 & 1.354 & Medium \\
\hline $\mathbf{3}$ & $\begin{array}{l}\text { The university provides rooms specially equipped for blended } \\
\text { learning. }\end{array}$ & 3.20 & 1.124 & Medium \\
\hline & Infrastructure and basic equipment & 3.27 & .947 & Medium \\
\hline
\end{tabular}

Table (4) shows that the arithmetic means have ranged between (3.20-3.40), where the item (1) which states "The University provides students with access to electronic libraries to access scientific references" is ranked first with the highest arithmetic mean of (3.40). This result is attributed to the ability of students to access through the databases at the University to electronic libraries to access the scientific references, except that students can enter the databases from inside the library, and the service is not fully available outside the library, while item (2) which states " The university provides rooms specially equipped for blended learning" is ranked last with an arithmetic mean of (3.20), and this result is consistent with the opinions of faculty members. More tellingly, this result is attributed, as previously indicated, to the novelty of applying the blended learning method at the University of Jordan, where there are classrooms specially equipped for blended learning, but these halls are not sufficient, and the arithmetic mean of the infrastructure and basic equipment as a whole has reached (3.27). 


\section{B. The used procedures and strategies}

Table 5

The Arithmetic Means and the Standard Deviations for the Items Related to the Used Procedures and Strategies in Descending Order According to the Arithmetic Means

\begin{tabular}{|c|c|c|c|c|}
\hline Rank & Items & $\mathbf{A M}$ & SD & Degree \\
\hline 1 & $\begin{array}{l}\text { There are clear instructions for how to interact electronically } \\
\text { between students, the faculty member, and educational content. }\end{array}$ & 3.22 & 1.166 & Medium \\
\hline 2 & $\begin{array}{l}\text { The faculty member deals with students' suggestions about the } \\
\text { blended learning with maximum effectiveness. }\end{array}$ & 3.10 & 1.142 & Medium \\
\hline 3 & $\begin{array}{l}\text { There are clear criteria for the student evaluation mechanism in the } \\
\text { blended learning courses. }\end{array}$ & 3.08 & 1.140 & Medium \\
\hline \multirow[t]{2}{*}{4} & $\begin{array}{l}\text { The university holds an explanatory meeting on how to use the E- } \\
\text { Learning Management System for students before starting blended } \\
\text { learning. }\end{array}$ & 2.82 & 1.123 & Medium \\
\hline & The used procedures and strategies & 3.06 & .943 & Medium \\
\hline
\end{tabular}

Table (5) shows that the arithmetic means have ranged between (2.82-3.22), as item (1) states, "There are clear instructions for how to interact electronically between students, the faculty member and educational content" is ranked first with the highest arithmetic mean of (3.22). This result may be attributed to the fact that the university issues publications that explain how students interact with members of the teaching staff and educational content, and the medium result may be because some students do not see these instructions. However, item (4) which states, "The university holds an explanatory meeting on how to use the E-Learning Management System for students before starting blended learning" is ranked last with an arithmetic mean of (2.82). This result may be attributed to the fact that the university is interested in holding explanatory meetings on how to use the e-learning management system for students before starting blended learning, but the medium result indicates that some students are absent from attending these meetings, and the arithmetic mean of the used procedures and strategies used as a whole is (3.06). The second field: The students' viewpoint towards the blended learning and its courses

Table 6

The Arithmetic Means and the Standard Deviations for the Items Related to the Students' Viewpoint towards the Blended Learning and its Courses in Descending Order According to the Arithmetic Means

\begin{tabular}{|c|c|c|c|c|}
\hline Rank & Items & AM & SD & Degree \\
\hline 1 & $\begin{array}{l}\text { Blended learning enhances students 'abilities in educational } \\
\text { technology and students' computer skills. }\end{array}$ & 3.72 & 1.133 & High \\
\hline 2 & $\begin{array}{l}\text { Blended learning supports positive student's attitudes towards self- } \\
\text { learning }\end{array}$ & 3.63 & 1.183 & Medium \\
\hline 3 & $\begin{array}{l}\text { Blended learning helps improve student's performance compared to } \\
\text { traditional education. }\end{array}$ & 3.63 & 1.131 & Medium \\
\hline 4 & Blended learning helps to organize student's time better. & 3.50 & 1.142 & Medium \\
\hline 5 & Blended learning helps in investing study meeting time efficiently. & 3.49 & 1.216 & Medium \\
\hline 6 & Educational content becomes easier with blended learning. & 3.46 & 1.191 & Medium \\
\hline 7 & Blended learning is more interesting and engaging. & 3.41 & 1.273 & Medium \\
\hline 8 & $\begin{array}{l}\text { Blended learning allows students to easily communicate with each } \\
\text { other and with faculty members. }\end{array}$ & 3.40 & 1.170 & Medium \\
\hline 9 & Blended learning helps in using collaborative learning & 3.38 & 1.202 & Medium \\
\hline 10 & $\begin{array}{l}\text { Blended learning clarifies the various topics in depth and in a way } \\
\text { that simulates reality. }\end{array}$ & 3.32 & 1.173 & Medium \\
\hline 11 & $\begin{array}{l}\text { Classroom meetings in the traditional learning system are preferred } \\
\text { over the blended learning system. }\end{array}$ & 3.30 & 1.300 & Medium \\
\hline \multirow[t]{2}{*}{12} & $\begin{array}{l}\text { Blended learning takes into account individual differences among } \\
\text { students. }\end{array}$ & 3.16 & 1.175 & Medium \\
\hline & The students' viewpoint towards the blended learning and its courses & 3.45 & .808 & Medium \\
\hline
\end{tabular}

Table (6) shows that the arithmetic means have ranged between (3.16-3.72), as the item (1) which states, "Blended learning enhances students 'abilities in educational technology and students' computer skills" is ranked first with the highest arithmetic mean of (3.72). This result may be attributed to the fact that students have to be familiar with computer skills to be able to enter the website and benefit from its services, and that the faculty members assist students when they are unable to do something when using the website. So, the repetitive use of the e-learning system Moodle contributes to enhancing students' abilities in the field of educational technology. However, item (12) which states "Blended learning takes into account individual differences among students" is 
ranked last with a mean of (3.16) and the arithmetic mean of the student's viewpoint towards blended learning and its courses as a whole is (3.45).

The third field: The reality of employing an E-Learning Management System for blended learning courses (students' attitudes towards blended learning courses)

Table 7

The Arithmetic Means and the Standard Deviations for the Items Related to the Students' Attitudes towards the E-Learning Management System for Blended Learning Courses in Descending Order According to the Arithmetic Means

\begin{tabular}{|c|c|c|c|c|}
\hline Rank & Items & $\mathbf{A M}$ & SD & Degree \\
\hline 1 & $\begin{array}{l}\text { I prefer having written communication in the E-learning } \\
\text { Management System with colleagues through forums for the blended } \\
\text { learning course. }\end{array}$ & 3.42 & 1.149 & Medium \\
\hline 2 & $\begin{array}{l}\text { I enjoy the direct assistance available in the e-learning management } \\
\text { system. }\end{array}$ & 3.42 & 1.177 & Medium \\
\hline 3 & $\begin{array}{l}\text { The e-learning management system helps me to identify the general } \\
\text { and specific goals of the subject to be studied. }\end{array}$ & 3.39 & 1.075 & Medium \\
\hline 4 & $\begin{array}{l}\text { I am satisfied with my use and effectiveness of the e-learning } \\
\text { management system. }\end{array}$ & 3.38 & 1.179 & Medium \\
\hline 5 & $\begin{array}{l}\text { I rely on an e-learning management system to prepare for my daily } \\
\text { activities. }\end{array}$ & 3.34 & 1.240 & Medium \\
\hline 6 & $\begin{array}{l}\text { The e-learning management system provides a service to attend the } \\
\text { educational meetings that you have missed. }\end{array}$ & 3.30 & 1.258 & Medium \\
\hline 7 & $\begin{array}{l}\text { The use of an e-learning management system enhances participation } \\
\text { in virtual learning sessions for blended learning. }\end{array}$ & 3.30 & 1.176 & Medium \\
\hline 8 & $\begin{array}{l}\text { The use of an e-learning management system allows easy } \\
\text { communication among students. }\end{array}$ & 3.26 & 1.197 & Medium \\
\hline 9 & $\begin{array}{l}\text { The e-learning management system participating in the blended } \\
\text { learning forums promotes teamwork among students. }\end{array}$ & 3.26 & 1.166 & Medium \\
\hline \multirow[t]{2}{*}{10} & $\begin{array}{l}\text { The e-learning management system provides an opportunity for me } \\
\text { to interact with faculty members in participating in planning } \\
\text { educational curricula. }\end{array}$ & 3.10 & 1.230 & Medium \\
\hline & $\begin{array}{l}\text { The Students' Attitudes towards the E-Learning Management } \\
\text { System for blended learning courses }\end{array}$ & 3.32 & .846 & Medium \\
\hline
\end{tabular}

Table (7) shows that the arithmetic means have ranged between (3.10-3.42), as the item (1) which states, "I prefer having written communication in the E-learning Management System with colleagues through forums for the blended learning course" is ranked first with the highest arithmetic mean of (3.42). This result is attributed to the fact that written communication is present in the system through chat rooms that help students communicate with each other or with teachers, as it is a feature provided by the electronic learning system (Moodle) that helps to keep students and teachers are in touch whenever they need. However, item (2) which states "I enjoy the direct assistance available in the e-learning management system", and this result means that students receive help from teachers or colleagues in the event of need and indicates the effectiveness of the system until if the student is not at the university, then he can receive assistance from others through the system itself. As for item (10) which states "The e-learning management system provides an opportunity for me to interact with faculty members in participating in planning educational curricula", it is ranked last, and this result may be attributed to the notion that the e-learning management system allows faculty members to design and publish referendums and take students 'opinions regarding academic courses, and this medium result indicates that some members use this feature, and are interested in taking the opinions of students. Importantly, this result is consistent with the results of the study of Gedera, Williams, and John Wright (2013), which indicates that students demonstrate their desire for communication and discussions through the Moodle system.

Q2. Are there statistically significant differences at the level of significance $(a=0.05)$ in the extent of the effectiveness of using blended learning at the University of Jordan from the students' viewpoint in teaching learning skills and scientific research course due to the variables of type of faculty and gender?

To answer this question, arithmetic means and standard deviations are calculated from the estimates of the effectiveness of using the blended learning at the University of Jordan from the students' viewpoint in teaching learning skills and scientific research course due to the variables of type of faculty and gender as shown in Table (8). 
Table 8

Arithmetic Means and Standard Deviations for the Estimates of the Effectiveness of Using the Blended Learning at the University of Jordan from the Students' Viewpoint in Teaching Learning Skills and Scientific Research Course due to the Variables of Type of Faculty and Gender

\begin{tabular}{|c|c|c|c|c|}
\hline 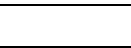 & Categories & AM & SD & Number \\
\hline \multirow[t]{2}{*}{ Gender } & Male & 3.20 & .751 & 300 \\
\hline & Female & 3.25 & .845 & 450 \\
\hline \multirow[t]{2}{*}{ Faculty } & Humanities & 3.38 & .755 & 377 \\
\hline & Scientific & 3.45 & .731 & 373 \\
\hline
\end{tabular}

The table shows the apparent variation in arithmetic means and standard deviations for estimates of the effectiveness of using blended learning at the University of Jordan from the students' viewpoint in teaching learning skills and scientific research course due to the difference in the categories of the variables of the type of faculty, gender. To indicate the significance of the statistical differences among the arithmetic mean, Two-way analysis of variance is used as shown in (Table 9).

Table 9

Two-way Analysis of Variance of the Effect of Type of Faculty and Gender on the Estimates of the Effectiveness of Using the Blended Learning at the University of Jordan from the Students' Viewpoint in Teaching Learning Skills and Scientific Research Course

\begin{tabular}{|l|l|l|ll|l|l|}
\hline $\begin{array}{l}\text { Source of } \\
\text { variance }\end{array}$ & $\begin{array}{l}\text { Sum of } \\
\text { squares }\end{array}$ & $\begin{array}{l}\text { Degrees } \\
\text { freedom }\end{array}$ & of & $\begin{array}{l}\text { Median } \\
\text { squares }\end{array}$ & $\begin{array}{l}\text { Value of } \\
\text { F }\end{array}$ & $\begin{array}{l}\text { Statistical } \\
\text { Sig. }\end{array}$ \\
\hline Gender & .002 & 1 & .002 & .003 & .855 \\
\hline Faculty & .618 & 1 & .622 & 1.004 & .422 \\
\hline Error & 490.012 & 748 & .619 & & \\
\hline Total & 485.544 & 749 & & & \\
\hline
\end{tabular}

Table 9 shows that there are no statistically significant differences at the level of $(\alpha=0.05)$ due to the effect of gender, as the value of $\mathrm{F}$ is 0.003 and with a statistical significance of 0.855 . It also shows that there are no statistically significant differences at the level of $(\alpha=0.05)$ due to the effect of the type of faculty, as the value of $\mathrm{F}$ is 1.004 and with a statistical significance of 0.422

\section{Recommendations}

In light of the results of the study, the current study recommends spreading the culture of blended learning among students and changing their views on the disadvantages of blended learning if all the results of students 'views about blended learning are medium, and this indicates that students are not greatly convinced of the importance of blended learning and its effectiveness in educational science, introducing students to the theatrical and practical importance of blended learning and conducting other studies looking at the effectiveness of blended learning from the viewpoint of faculty members.

\section{References}

Abu Musa, Mufid. A and Sous, Samir Abdel Salam. (2010). The effect of a blended learning program on teachers' ability to design and produce educational multimedia. Research presented to the first international conference "Blending and Mobile Learning: Capabilities and Challenges". Omani Society for Educational Technology, Oman.

Abdelatti, Mohammad. (2016). Blended Education Technology. Alexandria: The Educational Library.

Abd El-Gawad, T. S. (2011). Investigating the Efficacy of E-learning for Egyptian Higher Education (Order No. 10064882). Available from ProQuest Dissertations \& Theses Global. (1779950400). Retrieved March 21/2020 from https://search.proquest.com/docview/1779950400?accountid=27719

Amer, Tariq. (2015). E-learning and virtual education: Contemporary global trends. Cairo: The Arab Group for Training and Publishing.

Anzi, Shimma. (2013). The effect of blended learning strategy on achievement in the course of information technology and computer networks among students of the Department of Technology at the University of Tabuk and their attitudes towards it. Unpublished Master Thesis, Yarmouk University, Irbid, Jordan.

Ashhab, Nawal. (2015). E-learning: Recent trends in the education system. Amman: Amjad Publishing House.

Assaf, Iman. (2014). Evaluating the quality of e-courses in the light of teaching design standards according to the ADDIE model from the viewpoint of faculty members at the University of Jordan. Unpublished Master Thesis. University of Jordan, Amman, Jordan.

Ayyad, Fouad Ismail and Ashqar, Abdul Karim Mahmoud. (2011). The effect of using web 2.0 instrument in the Moodle system on achieving collaborative learning among students of information technology at the Islamic University. Journal of Information Studies, 17 (63), 1-11. 
Barakat, Kafa. (2014). Educational effects of the university of Jordan Students' use of the learning management system (MOODLE) and their attitudes towards it. Unpublished Master Thesis, University of Jordan, Amman.

Dershoy, Abdel-Hakim. (2019). The effect of the blended learning strategy on academic achievement and information retention for eleventh literary students in the subject of geography in Duhok Governorate Center / Iraq, 46 (1), 271-286.

Dousary, Ajab and Al-Jazzar, Nouf. (2017). The effect of blended learning on developing the trend towards mathematics among middle school students in the Kingdom of Saudi Arabia. Arab Studies in Education and Psychology, (87), 347 - 378.

Eraini, Siham. (2016). The reality of using math teachers in the intermediate stage for blended learning skills. Education World, 17 (53), 1-101.

Faraj, Suheir Hamdi. (2012). The effectiveness of developing an electronic course in educational technology and managing it via the Internet through the Moodle curriculum system to develop the concepts of e-learning for teachers of the Faculty of Education and measuring their attitudes towards the course. Journal of Educational and Psychological Sciences, 13 (3), 280-255.

Gomes, G. (2015). Blended Learning, Student Self Efficacy and Faculty an Interpretative Phenomenological Analysis. Order No. 3683157 Northeastern University, Ann Arbor: ProQuest.

Hyari, Lina. (2019). The effect of using the blended learning strategy on the achievement of Jordan University students in the English language subject. Dirast Journal, 46 (2), 23-34.

Khamis, Muhammad. (2013). Distance learning and open learning. Journal of the Egyptian Association for Educational Technology, 23 (1), 1-3.

Kiviniemi, M. T. (2014). Effects of a Blended Learning Approach on Student Outcomes in a Graduate-Level Public Health Course. BMC Medical Education, 14-47.

Maestas, B. A. (2016). The Impact of Enhanced Teacher Feedback on the Academic Outcomes of At-Risk Students in Blended Learning Environments (Order No. 10182434). Available from ProQuest Dissertations \& Theses Global. (1845306747). Retrieved March 22/2020. Retrieved from https://search.proquest.com/docview/1845306747?accountid=27719

Mahmoud, Abdel-Wahab. (2015). The effectiveness of a proposed program in the use of the e-learning management system (Moodle) in teaching and its effect on the achievement, skill and motivation aspect of achievement among students of commercial education at the Sohag Faculty of Education. Educational Journal, 40, 90-51.

Mannai, Abdullah Salem. (2016). The reality of employing e-learning and internet services from the viewpoint of teachers of basic subjects in Qatar Independent Secondary Schools. Journal of Educational and Psychological Sciences, 17 (1), 65-100.

Nawafleh, Rana. (2015). The use of faculty members at Yarmouk University for the e-learning system and the obstacles facing them, an unpublished Master Thesis, University of Yarmouk, Irbid, Jordan.

Otaibi, Kholoud Bint Ubaid Ayyaf. (2013). Designing a proposed e-learning management system at Princess Nourah Abdul Rahman University. Unpublished doctoral thesis. Princess Nourah Bint Abdul Rahman University, Saudi Arabia.

Rashidi, Ahmed. (2016). E-learning: Pros and cons as an educational vision. Giza: The Academic Library.

Salama, Ahmed. (2005). Blended learning: The natural development of e-learning, Department of Curricula and Teaching Methods. Sohag College of Education, South Valley University. Date of entry: 31/3/2018 retrieved from http://www.eulc.edu.eg/eulc_v5/Libraries/start.aspx?fn=DLibApp

Talba, Abdel Aziz. (2010). E-learning and educational technology developments. Mansoura: the modern library for publication and distribution.

Zamil, Majdi. (2017). Educational outcomes achieved by the blended curricula of students of the Faculty of Education at Al-Quds Open University: Jenin branch as a model. Palestinian Journal of Open Education, 6 (11): 81-98.

Zboun, Mamon. (2015). The degree of awareness of the students of the University of Jordan of the electronic curriculum (Moodle) and its relationship to some variables. The Arab Journal of Quality Assurance in University Education, 9 (25): 113-91.

Zboun, Mamon and Hamdi, Narges. (2017). The effect of using the "Moodle" system on developing the skill of self-learning among students of computer skills subject at the University of Jordan. Journal of Studies, Educational Sciences, 44, special issue, 189-203. 